\title{
EDUCAÇÃO DO CAMPO: PROFESSORES QUE ATUAM NOS ANOS INICIAIS DO ENSINO FUNDAMENTAL EM SALAS MULTIS DE MATO GROSSO
}

\section{FIELID EIDUCATION: TEACHING MULTIS CLASSES IN PRIMARY SCHOOL, MATO GROSSO, BRAZIL}

\author{
Dejacy de Arruda Abreu ${ }^{15}$ \\ Nilza Cristina Gomes de Araújo ${ }^{16}$
}

\section{RESUMO}

O presente artigo é resultado de um olhar reflexivo sobre do curso de Aperfeiçoamento em Educação do Campo voltado para classes Multis de Mato Grosso (MT). Se constituiu uma parceria COMFOR/IE/UAB/UFMT/ SECADI e SEDUC/MT. Atendeu uma demanda especifica de formação voltada para Educação do Campo com objetivo de criar espaços para novos estudos, trocas de experiências e aprofundamentos entre os profissionais que atuam em escolas campesinas. Procurou seguir a proposta da educação à distância em ambiente virtual de aprendizagem (AVA), de modo interativo mediante a organização metodologia e didática de oito disciplinas sendo sete de caráter pedagógico distribuída em 210 horas para atender quatro polos do Estado de Mato Grosso, ofertado para 200 alunos.

Palavras-chave: Educação do campo; Classes Multis; Formação continuada; Mato Grosso.

\begin{abstract}
This article is a reflexive account of the Field Education Improvement Course geared towards the Multis classes from Mato Grosso (MT, Brazil). It was created in partnership with COMFOR/IE/UAB/UFMT/ SECADI and SEDUC/MT. The course served the specific needs of Field Education aiming to create knowledge enhancement, spaces for new studies, and exchanges of experience between professionals working at Field schools. It is mostly an open and distance learning (ODL) online course using the virtual learning environment (VLE), or learning platform interactively for the organization, methodology and didactics of 8 school subjects, 7 of which are pedagogical, aiming at teacher formation. It was a 210-hour-course developed to attend four study poles for 200 students in the State of Mato Grosso, Brazil.
\end{abstract}

Keywords: Field education; Multis Classes; Continuing Education; Mato Grosso.

\section{INTRODUÇÃO}

Identificamos em nossos estudos voltados para Educação do campo, que os movimentos populares no Brasil foram responsáveis por muitas mudanças ocorridas na

\footnotetext{
${ }^{15}$ Doutoranda em Educação; Docente da Universidade Federal de Mato Grosso/ Instituto de Educação.

${ }^{16}$ Doutora em Educação; Docente da Universidade Federal de Mato Grosso/ Instituto de Educação.
} 


\section{REVISTA REAMEC}

\section{Revista da Rede Amazônica de Educação \\ em Ciências e Matemática}

década de 1980, foram seus esforços reivindicatórios embasados em suas demandas de necessidades que ajudaram a incluir na Lei de Diretrizes e Bases da Educação Nacional (LDB 9394/96), a temática da Educação do campo, a formulação de documentos legais que possibilitaram pensar os aspectos sociais, políticos e pedagógicos voltados às especificidades das escolas situadas no campo, ainda criaram e fortaleceram espaços de debate e construções de saberes e reinvindicações para essa causa.

Com isso, entendemos que a educação é um movimento constante de lutas, tensões e conquistas, seja ela no campo ou nas cidades. Mas, em cada canto, ela possui a sua especificidade. Tendo presente as lutas, trajetórias e histórias voltadas para o Campo, que assumimos ajudar a pensar o Curso de Educação para pessoas que moram, atuam profissionalmente e constroem suas vidas no espaço do campo. O que exigiu-nos atenta escuta e sensibilidade àqueles que ali estão.

Em atenção a isso, que acolhemos uma demanda da SECADI $^{17}$ em parceria com $\mathrm{COMFOR}^{18} / \mathrm{UAB} / \mathrm{UFMT}$ e SEDUC/MT, para tanto, ancoramos na LDB 9394/96 no que tange a especificamente o artigo 28 que contempla a orientação da formação para esta modalidade de educação do campo e que deixa explicitado, a relevância que há quando buscamos fortalecer os sujeitos no lugar em que realizam a sua prática pedagógica. Considera-se ainda de fundamental importância, a valorização do professor, em termos de se ter uma carreira profissional, como também, dos meios e estrutura física adequada, digna das escolas e das populações do Campo. Como nos alerta Arroyo (1999), ao dizer que "[...] não só há no campo uma dinâmica social, ou movimentos sociais no campo, também há um movimento pedagógico". É com isso que concordamos para essa feita.

Nesse entendimento e anseios, que assumimos o Curso de Aperfeiçoamento/extensão em Educação do campo tendo em vista as contribuições para a formação continuada do professor que atua nas escolas do Campo e atendem em salas Multis ${ }^{19}$ em Mato Grosso (MT). Mas, como temos um Estado de grandes dimensões, conforme a demanda e a localização dos polos das UABs, o curso foi ofertado para atender quatro polos que contemplam vários municípios do interior do mesmo do referido estado.

\footnotetext{
${ }^{17}$ A Secretaria de Educação Continuada, Alfabetização, Diversidade e Inclusão

${ }^{18}$ Comitê Gestor Institucional.

${ }^{19}$ Quando nos referimos a classes de aula miltiseriadas, faseadas, cicladas, Anos e séries.

Revista REAMEC, Cuiabá - MT, n.05, Volume 1, dezembro 2016, ISSN: 2318 - 6674

Revista do Programa de Doutorado da Rede Amazônica de Educação em Ciências e Matemática

http://revistareamec.wix.com/revistareamec
} 


\section{REVISTA REAMEC}
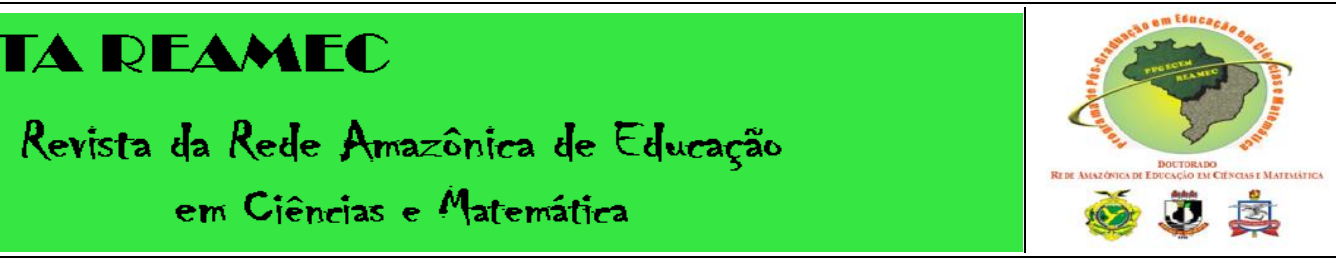

No curso, e para o curso, o Campo foi tomado como espaço de construção de saberes

e como produção intelectual daqueles que lá vivem. Nesse sentido que nos apoiamos em Santos; Lucini (2010), ao dizer que:

[...] é necessário que se pense numa formação de professores que considere as dificuldades de acesso à formação pelos professores. Mas, também, que considere que tanto eles, quantos seus alunos, detêm saberes que devem fazer parte de currículo próprio, porque ser professor do campo é igual a qualquer lugar do Brasil, mas cada região detém especificidades próprias, que devem ser consideradas durante o processo formativo do docente para atuar na área rural (2010, p.8),

Entendemos no víeis da interlocução desses autores, a importância do Campo na expressão da Educação do Campo sendo necessária para qualificar e demarcar as práticas pedagógicas pertinentes à educação, tendo este o seu currículo voltado à espacialidade, às temporalidades e às especificidades do campo. Compreendendo a relevância de destacar sua particularidade como lugar de formação do professor. Assim, o curso em questão, se propões a ajudar a qualificar a ação dos sujeitos envolvidos na ação educadora do e para o campo.

Nesse movimento de aprendizagens compartilhadas, a intencionalidade acadêmica e social buscou também suscitar reflexões sobre a educação para além das fronteiras e limites hegemônicos dos saberes instituídos. Os quais são entendidos como importantes e válidos, porém não são os únicos. Neste sentido, a Educação do Campo, como instrumento/ferramenta de ação político-social, assume função estratégica na afirmação da identidade campesina e na formulação de um novo projeto político para o campo.

Nessa perspectiva, o curso de aperfeiçoamento de professores do Campo, enquanto uma estratégia política e educativa é uma das formas de fortalecimento dos professores do Campo e do exercício democrático configurando-se como instrumento pedagógico importante para a afirmação da prática e fortalecimento da cidadania.

Para ampliar nossa compreensão e reflexão Fernandes; Molina, (2005),

[...] defendem o campo como espaço de particularidades e matrizes culturais. Esse campo é repleto de possibilidades políticas, formação crítica, resistência, mística, identidades, histórias e produção das condições de existência social. Cabe, portanto, à educação do campo, o papel de fomentar reflexões que acumulem forças e produção de saberes, no sentido de contribuir para a negação e/ou desconstrução do imaginário coletivo acerca da visão hierárquica que há entre o campo e a cidade. Essas são ações que

Revista REAMEC, Cuiabá - MT, n.05, Volume 1, dezembro 2016, ISSN: 2318 - 6674 


\section{REVISTA REAMEC}

Revista da Rede Amazônica de Educação

em Ciências e Matemática

podem ajudar na superação da visão tradicional do imaginário social do jecatatu e do campo como espaço atrasado e pouco desenvolvido.

Desta forma, a educação do campo nos ajuda a ampliar o diálogo com a singularidade, a diversidade cultural e os tempos desse espaço social. Com isso, foi possível ao seu público a compreensão e acesso à complexa sociedade moderna, que produz não só novas formas de trabalho, mas, também, diversidades e diferenças sociais, econômicas, políticas, culturais e ecológicas. Entendendo que a Educação do campo está dentro desse movimento de rápidas transformações sejam micros ou macros. E que do educador do campo com suas demandas surgem contribuições para pensarmos a educação numa perspectiva de um projeto social.

O curso de Educação do campo foi construído intitulado: Educação do campo: o trabalho docente de professores que atuam nos anos iniciais do Ensino Fundamental em Mato Grosso. Foi estruturado com 8 disciplinas, sendo a primeira disciplina voltada para o sistema $\mathrm{AVA}^{20}$ e as demais pedagógicas.

Nessa perspectiva, o curso, ofertou 200 (duzentas) vagas distribuídas em 4(quatro) polos UAB/UFMT no Estado de Mato Grosso atendendo os municípios de Cuiabá, Colíder, Juína e Ribeirão Cascalheira (sendo 50 vagas para cada Polo), o que é um recorte diante da dimensão de escolas do campo em Mato Grosso. Cada polo congrega vários municípios circunvizinhos do mesmo.

\section{PERCURSO METODOLÓGICO EMPREGADO PELO CURSO}

A tessitura cotidiana do curso se fez com a atuação dos cursistas nos fóruns de cada disciplina, leituras, vídeos e postagens de atividades nas bases de dados. Foi uma construção coletiva primando por uma interlocução entre a teoria e a prática numa perspectiva da alternância.

A proposta centrou-se na forma de trabalho da Educação a Distância (EaD) procurando incentivar o professor do Campo a entrar nas salas Ambientes, tomando-as como espaço oportuno de estudo, trocas de experiências e aprofundamentos. Contagiados por esse espaço, e o que ele oferece, que ele pudesse estimular também os seus estudantes no desenvolvimento da responsabilidade, da autonomia intelectual em um processo de ensino e

${ }^{20}$ Ambiente Virtual de Aprendizagem (AVA)

Revista REAMEC, Cuiabá - MT, n.05, Volume 1, dezembro 2016, ISSN: 2318 - 6674

Revista do Programa de Doutorado da Rede Amazônica de Educação em Ciências e Matemática

http://revistareamec.wix.com/revistareamec 


\section{REVISTA REAMEC}

\section{Revista da Rede Amazônica de Educação \\ em Ciências e Matemática}

aprendizagem criativo, vivenciado e de qualidade. Com essa participação ativa protagonizada por eles, aflorar a valorização das populações do campo, dos seus saberes respeitando seu espaço e cultura. Foram esses valores, estratégias e motivações que perpassam o curso de aperfeiçoamento.

A metodologia desenvolvida foi de caráter semipresencial com encontros presenciais e a distância a partir da interatividade do tutor com os cursistas on-line na plataforma Moodle. O curso teve como referência para o desenvolvimento das atividades o AVA administrado pela STI/COMFOR/UFMT. Os tutores acompanhavam os cursistas que, em alguns casos, formavam grupos de estudo a fim de facilitar a leitura, a compreensão e a elaboração de novos textos de maneira virtual. O que queremos dizer com isso, que a distância, ou as limitações oriundas dela, em muitos momentos fizeram nascer no professor cursista um desejo maior de concluir o curso.

A proposta de Formação Continuada para educadores que atuam na educação do campo alicerçou-se na compreensão de que a premissa principal da formação continuada consiste na criação de oportunidades para que o educador pense, reflita especificamente nas três dimensões fundamentais das relações educativas: o professor, o aluno da educação do campo e o conhecimento.

Buscou-se neste curso articular a teoria e a prática dos nossos professores do campo com o objetivo de criar condições teórico-metodológicas para que esses educadores na condição de cursistas fizessem estudos, diagnósticos e projetos que problematizassem os elementos concretos de sua realidade, possibilitando desenvolver um projeto de intervenção como resultado de suas vivências no curso em diálogo com sua realidade e que fosse construído coletivamente.

O curso buscou valorizar, também, a auto-organização dos estudantes/ profissionais do campo, no intuito de suscitar espaços para a autonomia e o protagonismo destes no processo educacional.

Entendemos, nesse processo de estudos, que para atingirmos os objetivos formativos, foi e é imprescindível que o trabalho pedagógico fosse organizado no processo de alternância entre os períodos de atividades didáticas presenciais e atividades de leitura, pesquisas 


\section{REVISTA REAMEC}

\section{Revista da Rede Amazônica de Educação \\ em Ciências e Matemática}

diagnósticas locais, a serem realizadas nas realidades tendo presentes as suas especificidades. Tempo Comunidade (TC), acompanhados pelos docentes de forma modalidade à distância (EAD), utilizando as diferentes ferramentas educativas do AVA. Para possibilitar as atividades propostas, os componentes curriculares foram organizados por Áreas de Conhecimentos intercalados com atividades do TC, garantindo assim as condições de permanência dos/as cursistas no curso.

Dentro dessa perspectiva e foi organizado com uma carga horária de 210 horas. Para a concretização dessa carga horária, foram distribuídas 170 horas na modalidade a distância.

As salas Ambientes seguiram uma dinâmica didática pedagógica do caminho ou das trilhas a serem perseguidas, que se constituíram em áreas de conhecimentos: Ambiente Virtual de Aprendizagem e contextos, fundamentos teóricos práticos da Educação do Campo; Planejamento, currículo e práticas Pedagógicas na Educação do Campo; Linguagens: fundamentos e metodologias na Educação do Campo e Ciências da Natureza; fundamentos e metodologias na Educação do Campo.

Em cada disciplina/ Módulo foi aberto um espaço virtual denominado Fórum de discussão, debates, dúvidas sobre as leituras feitas, descoberta e afirmações de aprendizagens que ficou aberto até o final do curso. Neste espaço, o cursista, sempre que pode, interagia com o professor formador para tirar dúvidas, solicitar esclarecimento sobre a temática estudada e trazia as suas contribuições;

Cada Área de Conhecimento comportou duas disciplinas, cada disciplina tinha uma base de dados na qual o cursista postava a atividade que correspondia a cada uma das disciplinas; A partir do $3^{\circ}$ módulo, entrou em cena o Projeto Vivencial que foi de intervenção e permeou os demais módulos subsequentes.

Como parte integradora do curso, aconteceu, simultaneamente nos quatro (4) polos onde foi ofertado o curso (Ribeirão Cascalheira, Colíder, Juína e Cuiabá), o Seminário socializador. Nessa oportunidade, os cursistas compartilharam a experiência realizada no curso e no chão da escola do campo trazendo suas vivências concretas a partir do Projeto de Intervenção feito para sua classe ou para sua escola como um todo.

\section{RESULTADOS OBTIDOS}




\section{REVISTA REAMEC}

\section{Revista da Rede Amazônica de Educação \\ em Ciências e Matemática}

Pôde-se perceber que alguns estudantes/professores da rede de Ensino Municipal ou

Estadual que não frequentavam um curso dessa natureza há algum tempo, ou nunca frequentaram, apresentaram dificuldades em desconstruir conceitos/concepções no processo ensino-aprendizagem, como de fazer a vinculação dos mesmos com sua realidade escolar. E houve outros que chegaram no ano de 2014 às escolas do Campo, constituindo o curso, seus primeiros contatos com a literatura específica sobre a Educação do Campo.

Mediante algumas observações e entendimentos oriundos da demanda da atuação do cursista frente ao curso, sentimos a necessidade de se instigar mais com o estudante via textos/conteúdos/ vídeos/ fóruns referentes a essa práxis educativa do Campo, pois percebemos o quanto sentiam privilegiados em estar fazendo o curso chegando a mencionar sobre a atenção à educação do campo por parte da UFMT. De alguma forma em seus depoimentos diziam que se sentiam acolhidos e ouvidos em suas necessidades ou parte delas. E isso, era gratificante diante do pouco que estávamos oferecendo. Nesse momento, ou em vários outro compreendemos o papel social e formador da universidade e o que ela representa no imaginário e no estado da arte da profissionalização de nossos professores.

Mas, foram surgindo muitos fatores limitadores para execução do curso, afinal estávamos lidando com uma diversidade de lugares e públicos com culturas locais específicas.

Havia, um movimento tanto dentro como fora do curso, o qual nos possibilitou detectar algumas dificuldades e desafios que dizem respeito ao universo das escolas, bem como de seus profissionais envolvidos com este curso E, para melhor evidenciarmos esse universo observado, salientamos alguns pontos que entendemos importantes ressaltar aqui:

a) alguns alunos apresentaram dificuldades de domínio de programas básicos de informática/internet - requisito importante para fazer o curso. Desse modo, muito tempo foi destinado para tentar fazer estes cursistas entenderem alguns procedimentos técnicos, o que consumiu tempo que poderia ser aproveitados no aspecto pedagógico (hora aula) e sobre suas primeiras leituras exigiu dos tutores exaustivo acompanhamento tanto nos polos presenciais como em lócus, sim lá no chão onde o aluno/cursista atuava. 


\section{REVISTA REAMEC}

\section{Revista da Rede Amazônica de Educação \\ em Ciências e Matemática}

b) outros, só conseguiam acessar/baixar os textos para estudos e só voltavam para plataforma para postagem das atividades avaliativas. Isso sim, podemos dizer que foi um curso à distância e enfrentado pela determinação daqueles que teimavam em concluí-lo.

c) para outros alunos tivemos que copiar todo material em CDs e fazer chegar às escolas; os estudos/ atividades, algumas vezes, foram realizados e enviadas via correio ou nos ônibus de linha. Outros precisavam andar quilômetros, na esperança de encontrar uma internet funcionando naquele dia, contando com carona para voltar para casa. E esses nos pediam, por favor, para não os excluirmos do curso, pois já se sentiam excluídos de diversos recursos e oportunidades de formação.

Foi com esse perfil de estudantes professores que trabalhamos, pessoas com dificuldades no contato com o curso online, porém também, corajosas e sedentas de formação.

\section{NOVOS OLHARES E POSSIBILIDADES: 'TRANSVER'}

Diante do que o curso nos fornecia através dos nossos professores do campo, os nossos olhos de pesquisadores se encheram de curiosidades para desenvolver uma pesquisa dentro desse curso no intuito de mapear os conhecimentos aprendidos pelos cursistas através das salas ambientes, bem como perceber se estes conteúdos, trabalhados nas salas, foram oportunos para o exercício cotidiano da docência.

Recortamos, deste universo, uma amostragem singular para desenvolvermos a pesquisa com participação de 3 alunas do curso de Pedagogia da UFMT campus sede de Cuiabá, bem como, duas tutoras junto ao Polo de Cuiabá ${ }^{21}$. Os 14 (quatorze) professores/ cursistas se dispuseram a ser sujeitos desta pesquisa e nos concederam seus relatos. Estes professores pertencem as localidades: Bom Jardim, Nobres, Acorizal e Chapada dos Guimarães.

Para essa feita, as pesquisadoras colocaram os pés na estrada e foram em lócus ouvir as narrativas históricas e pedagógicas dos nossos professores informantes. A partir desses relatos orais dos professores de classes multi, realizou-se uma investigação de natureza empírica, em que se priorizou as vozes destes docentes, mediante entrevistas

\footnotetext{
${ }^{21}$ O Polo de Cuiabá enquanto espaço online compreendeu os seguintes municípios: Várzea Grande, Pontes e Lacerda, Acorizal, Chapada dos Guimarães, Jangada, Nobres, Diamantino, Rondonópolis, Bom Jesus do Araguaia, Querência e Tangará da Serra.

Revista REAMEC, Cuiabá - MT, n.05, Volume 1, dezembro 2016, ISSN: 2318 - 6674

Revista do Programa de Doutorado da Rede Amazônica de Educação em Ciências e Matemática

http://revistareamec.wix.com/revistareamec
} 


\section{REVISTA REAMEC}

\section{Revista da Rede Amazônica de Educação \\ em Ciências e Matemática}

semiestruturadas, material básico de onde as percepções e entendimentos dos professores foram apreendidos e interpretados. No momento presencial da entrevista observou-se, a alegria e o compromisso com a causa do Campo, bem como as principais problemáticas vivenciadas por estes docentes diante de uma realidade tão complexa.

As questões utilizadas para coleta de dados se organizaram em dois blocos. O primeiro grupo de questões buscou trazer informações gerais dos participantes da pesquisa, caracterizando desde a idade, perpassando pela formação acadêmica dos docentes até a questão de se ter prazer em atuar na educação do campo. Já o segundo grupo de perguntas versou sobre o desenvolvimento do curso e seu aproveitamento no cotidiano das práticas pedagógicas dos docentes.

Sobre o primeiro grupo de questões que procuraram caracterizar os 14 (quatorze) sujeitos entrevistados, bem como descrever sua trajetória de formação acadêmica, pode-se afirmar que dos 14 entrevistados, 13 foram professoras e 01 era professor, a maioria são naturais de Matogrosso, atuam em classes multis e moram nas comunidades em que trabalham. O que de certa forma pode facilitar a realização das aulas, uma vez que o professor não precisa caminhar longas distâncias para chegar à escola em que trabalha. Mas, pelo que mapeamos o curso, essa não é a realidade de todas as escolas e professores que realizaram o presente curso, por isso, esse é um dado importante a ser assinalado nesta pesquisa. Além de ser importante é relevante, pois mostra que há sinais de maior presença de profissionais de educação morando na comunidade de origem da escola ou próximas dela. Mostra ainda, que a formação continuada ofertada pelas secretarias e projetos diversos de alguma maneira pouco está alcançando essa parcela de trabalhadores da educação, os quais decidem mesmo diante de suas fragilidades de formação continuar investindo seus esforços e sonhos junto ao homem e a mulher do campo.

Os professores entrevistados possuíam formação em Pedagogia (eram formados no curso ou estavam cursando), dos 14 professores, 08 são especialistas, dado que demonstra o interesse dos professores pela busca de formação continuada, inclusive reafirmado quando se matricularam neste curso de Aperfeiçoamento em Educação no Campo que estamos descrevendo. 


\section{REVISTA REAMEC}
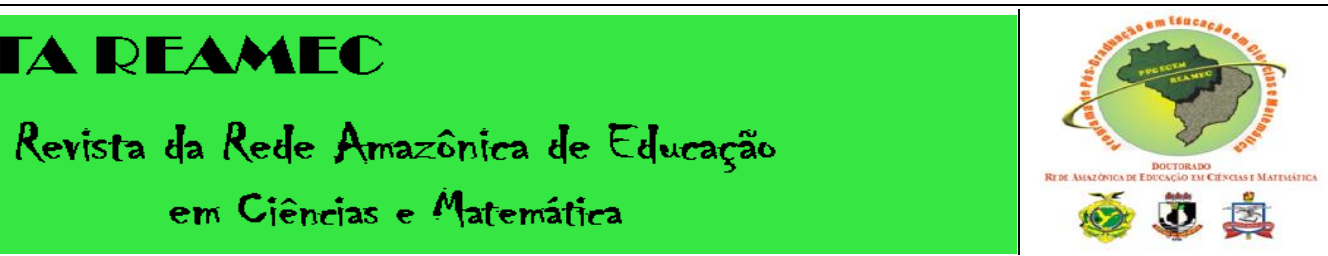

No que diz respeito ao tempo de formação destes educadores, assinala-se que dos 14 entrevistados, 06 professores se formaram há uns 12, 15 anos e possuíam uma trajetória na carreira docente maior do que a dos outros. Houve 08 professores que foram caracterizados como iniciantes no exercício do magistério porque o período de sua formação e atuação na carreira docente eram menores. Ao longo do curso em fóruns e mensagens com relatos de experiências encontramos uma professora que disse que o curso em questão, se constitua suas primeiras leituras sobre a educação do campo de modo mais sistematizado.

Neste panorama geral de caracterização dos sujeitos, pode-se acrescentar, ainda, que a maioria só trabalha em uma escola, somente 01 professora trabalha mais de um período, pois atua, também, na Secretaria de Educação do Município.

Pôde-se perceber, em suas respostas, que os quatorse docentes evidenciaram os aspectos positivos referentes à aceitação, contribuição e aprendizado proporcionados pelo curso alguns tomaram como pontos positivos, conforme depoimentos a seguir:

Veio contribuir muito com nosso pedagógico, como também enriquecer nosso conhecimento". (Professora A) ${ }^{22}$

"Trouxe aprendizagem e conhecimento profundo para a educação do campo. Foi ótimo". (Professora B)

"O curso de aperfeiçoamento em educação do campo online está sendo muito rico em conhecimento e contribuindo de forma significativa para a minha formação e interação com as tecnologias na educação no campo e com a minha prática na sala de aula". (Professora C)

"Os Pontos positivos se referem ao conhecimento, troca das experiências, as informações sobre o currículo do campo, as novas diretrizes, as preocupações em formar os professores do campo". (Professora L)

"Os pontos positivos foram o meu aprendizado que melhorou muito, e as tutoras foram muito colaborativas". (Professora L)

Pontos positivos: ler textos que contribuem com a educação no campo e conhecer o que é CIPEC e também nos dá esperança de que a educação no campo ainda vai ser como deve ser." (Professora O)

Verificamos nessas colocações dos professores, os anseios dos mesmos por formação continuada dentro de sua área de atuação e realidade. Sentem necessidade de compartilhar suas experiências, lutas e conquistas. E o curso, de certa forma, se constituiu uma janela que possibilitou olhar para fora e para dentro da escola tendo presente a realidade social como um todo.

\footnotetext{
${ }^{22}$ Os professores, em seus depoimentos, serão identificados pelas letras do alfabeto para preservação de seus nomes e garantia de fidedignidade dos dados. Como são 14 professores serão identificados da letra A até a letra O. Porém, aquí trouxemos alguns dos depoimentos.
}

Revista REAMEC, Cuiabá - MT, n.05, Volume 1, dezembro 2016, ISSN: 2318 - 6674

Revista do Programa de Doutorado da Rede Amazônica de Educação em Ciências e Matemática

http://revistareamec.wix.com/revistareamec 


\section{REVISTA REAMEC}

\section{Revista da Rede Amazônica de Educação \\ em Ciências e Matemática}

Estes aspectos positivos, apresentados pelos professores, parecem refletir os resultados das políticas públicas ofertadas pelo governo federal e direcionadas à população do campo. Nota-se, ao longo da história da educação de nosso país, que os professores de classes multis pouco tiveram, ao longo dos tempos, formação específica para atuarem em suas realidades. Desta forma manifestam-se positivamente, à participação neste curso.

Esses pontos levantados e abordados revelam a consciência dos envolvidos no que se refere ao curso e seu comprometimento com a proposta da escola do campo. Mesmo tendo dificuldades de acesso pelos motivos já explicitados, o material disponibilizado no curso sejam os textos, artigos, livros e vídeos chegaram aos seus destinatários, os quais, em sua maioria, conseguiram socializar com os demais colegas da escola.

Mas, nem tudo foi perfeito, quanto aos pontos negativos, os professores foram unânimes em afirmar que a rede de internet que eles puderam contar enquanto estavam cursando o aperfeiçoamento não foi boa. Tanto a velocidade utilizada para navegação, como oscilação da rede combinada a distância para se chegar a uma lan house para aqueles que não têm computador em casa, trouxe desestímulo e até desistência. Todos precisaram esforçar-se para dar continuidade aos seus estudos. Pelos depoimentos e mensagens durante todo curso, entendemos a necessidade de mais encontros ou momentos presenciais para curso dessa natureza, onde a distância e a carência de recursos tecnológicos adequados e que funcionem podem comprometer todo o bom desempenho de um curso. Mesmo diante das fragilidades, alguns alunos conseguiram criar estratégias de estudos, fizeram grupos de estudos, baixavam todo o material em CD. Isso também ocorreu em várias localidades, a ponto da coordenação do curso, com ajuda de tutores, disponibilizar em CD o material do curso para realização dos estudos. Desse modo muitos puderam realizar o curso cheio de obstáculos materiais numa grande maratona.

Esse curso nos ajudou a iniciarmos novas reflexões de formação para essa modalidade de Educação, como diz Arroyo (2004) a nos indagar,

Como educadores, temos de ter sensibilidade para essa dinâmica social, educativa e cultural, e perguntar-nos que novos sujeitos estão se constituindo, formando, que crianças, jovens, adultos, que mulheres, que professoras e professores, que lideranças, que relações sociais de trabalho, de propriedades que valores estão sendo aprendidos nesse movimento e dinâmica do campo. [...]. Como educadores temos de olhar e entender como 


\section{REVISTA REAMEC}

Revista da Rede Amazônica de Educação

em Ciências e Matemática

nesse movimento social vêm se formando, educando um novo homem, uma nova mulher, criança, jovem ou adulto (p. 70).

Diante disso concordamos com o referido autor, num entendimento que precisamos ser sensíveis diante da dinâmica social que abarcam e ditam mudanças que nem sempre contemplam os anseios das realidades campesinas com suas peculiaridades educacionais.

\section{CONSIDERAÇÕES FINAIS}

O curso em questão nos possibilitou uma aproximação maior do universo das escolas do campo de Mato Grosso e a entendê-las a partir de suas realidades factuais.

Foi relevante, as narrativas dos professores, pois muitos afirmaram que o curso se constituiu o lugar do diálogo, espaço socializador de experiências e aprendizados. Mesmo sendo um curso à distância, os alunos conseguiam ser ouvidos pelos professores e tutores, talvez não na sua totalidade. Manifestaram suas inquietações e celebravam o quando o material conseguia traduzir ou dizer-lhes algo que podiam usar seguramente em suas realidades.

Isso possibilitou entendermos que a realidade das escolas do campo anseia por uma atenção mais efetiva, cuidadosa e que atenda às reais necessidades dos educandos e educadores do campo. E que a UFMT deve assumir esse compromisso mais efetivamente como projeto continuo para atender essa demanda de formação permanente.

Todavia, o trabalho online de um curso dessa natureza e demanda, exige tempo, perseverança e compromisso com a causa do Campo. Não se constitui um trabalho que se garanta com precisão, início e fim dentro de um cronograma fechado, pois os tempos do campo com suas distâncias e múltiplas necessidades, algumas até emergentes não nos autorizam tratamento igual aos demais cursos de outras naturezas ofertados online.

\section{REFERÊNCIAS}

ARROYO, Miguel Gonzalez; CALDART, Roseli Salete; MOLINA, Mônica Castagna. Por uma educação do campo. Petrópolis: Vozes, 2004.

ARROYO, M. Ciclos de desenvolvimento humano e formação de educadores. Educação \& Sociedade, Campinas, v. 20, n. 68, p. 143-161, dez. 1999. 


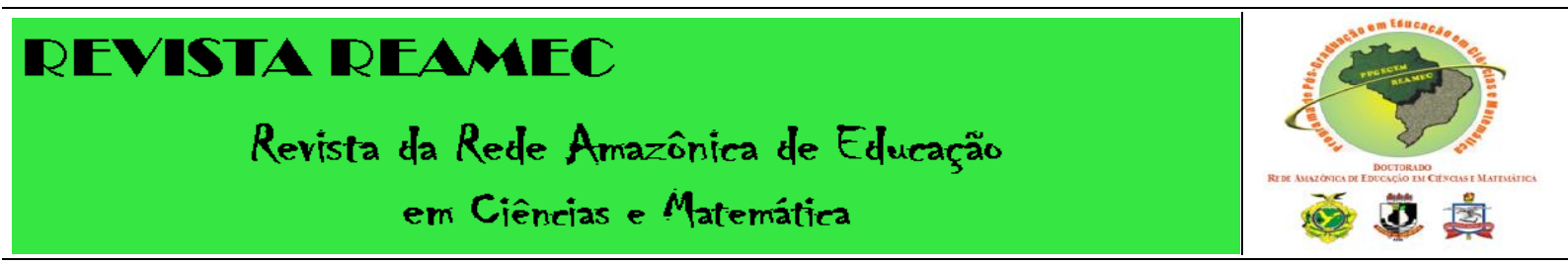

BRASIL. Lei de Diretrizes e Bases da Educação Nacional. Lei número 9394, 20 de dezembro de 1996.

FERNANDES, B. M.; MOLINA, M. C. \& JESUS, S. M. S. A. (org.). Contribuições para a construção de um projeto de educação do Campo - Brasília, DF: Articulação Nacional Por uma Educação Básica do Campo, 2004. Coleção Por uma Educação Básica do Campo, nº 5.

\section{SECRETARIA DE ESTAdO DE EDUCAÇÃO DE MATO GROSSO. Política Pública de Educação de Jovens e Adultos do Estado do Mato grosso, 2009.}

SILVA, Tomaz Tadeu da (1999). Documentos de Identidade: uma introdução as teorias do currículo. Belo Horizonte: Autênticas.

VIEIRA, Angelina de Melo. A escola e seu currículo na mediação de Projetos societários. In: VIEIRA, Angelina de Melo. Currículo em ação: implicações na construção de uma escola democrática, Neterói/RJ. 2009, p.70-84. 